\title{
An Experimental Study on Attenuation of Radiant Heat Flux from Flame through Water Droplets
}

\author{
KIYOTO USUI ${ }^{1}$, and KEN MATSUYAMA ${ }^{2}$ \\ ${ }^{1}$ Nohmi Bosai Ltd., \\ 2-42 Sakae, Misato-shi, Saitama 341-0043, Japan \\ ${ }^{2}$ Center for Fire Science and Technology, \\ Tokyo University of Science, \\ 2641 Yamazaki, Noda-shi, Chiba 278-8510, Japan
}

\begin{abstract}
Suppression system by water spray such as sprinkler system is installed in many buildings and well-known as one of highly effective fire protection methods for enclosure. On the other hand, sprinkler system (hereinafter referred to as SP) would have other effects, such as cooling effect in a compartment, cooling effect of building structure and attenuation of radiant heat flux from fire. In this paper, attenuation of radiant heat flux through water droplets were investigated by full-scale experiments. The fuels were used $n$ heptane and ethanol for comparison of influence of soot particle. 5 kinds of sprinkler nozzles were used in the experiment. Firstly, the fundamental data of the nozzles and flame such as droplets diameter, droplets velocity and distribution of water droplets and radiant spectrum of flame were investigated. Moreover, absorption and transmittance of radiant heat flux was calculated by the Mie theory. And also, an improved prediction model on radiant spectrum was used to predict the radiant spectrum of flame. Thus, absorption and transmittance of radiant heat flux can be calculated by above flame data and fundamental SP data. As the result of calculation parametrically, radiant heat attenuation increases with decreases of droplets diameter. And, it increase approximately linearly depends on amount of total droplets.
\end{abstract}

KEYWORDS: radiant heat flux, attenuation factor, water droplet, Mie theory, full-scale fire experiment

\section{NOMENCLATURE LISTING}

\begin{tabular}{|c|c|c|c|}
\hline$a$ & Radius of water droplet $(\mu \mathrm{m})$ & $e_{\lambda}$ & Emission spectrum of flame (-) \\
\hline$H F G(N)$ & $\begin{array}{l}\text { Radiant heat flux by heat } \\
\text { flux gauge }[\mathrm{N}]\left(\mathrm{W} / \mathrm{m}^{2}\right)\end{array}$ & $H F G(W)$ & $\begin{array}{l}\text { Radiant heat flux by heat flux gauge } \\
{[\mathrm{W}]\left(\mathrm{W} / \mathrm{m}^{2}\right)}\end{array}$ \\
\hline$I$ & Attenuated emissive power $\left(\mathrm{W} / \mathrm{m}^{2}\right)$ & $I_{\lambda}$ & Measured emissive power $\left(\mathrm{W} / \mathrm{m}^{2}\right)$ \\
\hline$I_{\lambda d}$ & $\begin{array}{l}\text { Attenuated emissive power for each } \\
\text { wavelength }\left(\mathrm{W} / \mathrm{m}^{2} / \mu \mathrm{m}\right)\end{array}$ & $n(x)$ & Droplet density (droplets $/ \mathrm{m}^{3} / \mathrm{min}$ ) \\
\hline$\imath_{i}$ & Droplet number (droplets) & $Q_{a b s}$ & Coefficient of absorption by water (-) \\
\hline$O$ & Coefficient of scattering by water (-) & & \\
\hline
\end{tabular}

\section{INTRODUCTION}

Automatic suppression system by water spray such as sprinkler system (hereinafter referred to as SP) is installed in many buildings and well-known as one of highly effective fire protection methods for enclosure. To date, most of researches on sprinkler systems and water mist have focused on the suppression performance. On the other hand, sprinkler system would have other secondary effects such as follows can be expected of these automatic suppression systems by water spray as shown in Fig. 1 [1].

- Cooling effect of the atmospheric temperature within the compartment

- Cooling effect of the temperature of the surrounding structure

- Attenuation of the radiant heat from the fire source 


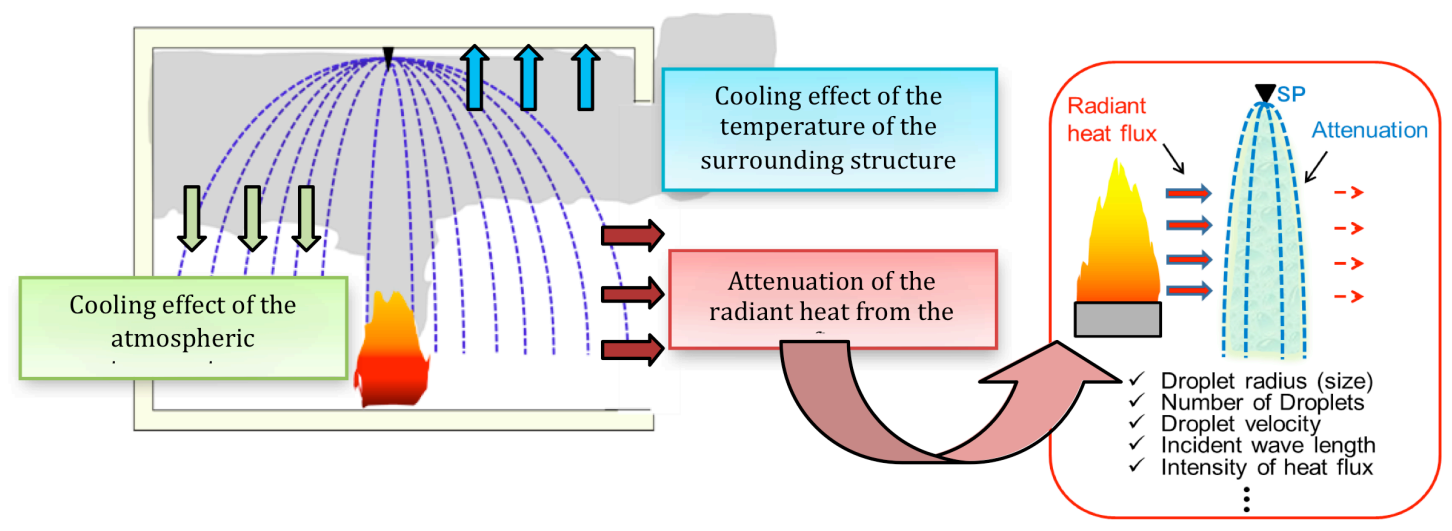

Fig. 1. Conceptual diagram of the effects by water spray in a compartment fire.

In particular, reports relating to third item have primarily targeted facilities for water-screen or curtain discharge [2-4], such as drencher systems, and cases targeting sprinkler systems are scarce. Recently, researches considering the absorption of radiant heat by water droplets using the Mie theory has been reported [3-6], but such researches are of local scope and are not systematic. Therefore, in this study, we conducted a systematic experiment targeting the attenuation of the radiant heat from the fire source, and a theoretical analysis. The purpose of this study is to develop a prediction model for the radiant heat attenuation, such that the model is compatible with various conditions. When targeting the attenuation of the radiant heat from the fire source, it is necessary to know the characteristics of both the fire source (flame) that emits the radiation and the water droplets that scatter/absorb it. We first collected fundamental data about sprinkler nozzles (droplet size, droplet velocity, and distribution of water spray) and about the flame (its emission spectrum). And then, measurements of the radiant heat attenuation were carried out by using a full-scale fire compartment, combining several sprinkler nozzles and fuels of differing combustion characteristics as parameters. Furthermore, the Mie theory was applied to develop a calculation model relating to the absorption/scattering of radiant heat. The model was then verified based on the fundamental data about the sprinkler nozzles which were acquired in the experiments. In addition, a prediction model of the emissive power from the fire source (flame) in response to the type of combustion was developed by improvement of a past prediction model on flame emission spectrum, and conducted validations.

\section{EXPERIMENTAL STUDY ON RADIANT HEAT ATTENUATION}

\section{Outline of Experiment}

As stated above, fundamental sprinkler nozzles data and flame emission spectrum data are essential in order to predict radiant heat attenuation. First, data on the basic characteristics of the sprinkler nozzles and flame were collected. After collected fundamental sprinkler nozzles flame data, the experiment was carried out using a full-scale fire compartment on radiant heat attenuation by the water droplets of a sprinkler system. The effect of the smoke layer (soot) was also compared by carrying out the experiment both inside and outside the compartment.

\section{Fundamental data about sprinkler nozzles}

(a) Distribution of water spray; Fig. 2 shows the full-scale fire compartment and an outline of the experimental setup. A Square shaped containers with $0.1 \mathrm{~m}^{2}(=0.33 \mathrm{~m} \times 0.33 \mathrm{~m})$ were used, and placed between the fire source and a radiant heat flux gauges located $0.5-3.5 \mathrm{~m}$ every $0.5 \mathrm{~m}$ for measuring the mass flux and distribution in the compartment. Water discharge pressure was $0.1 \mathrm{MPa}$ every nozzles as shown in Fig. 2.

(b) Droplet size; A laser (Nd:YAG, $120 \mathrm{~mJ}, 532 \mathrm{~nm}$ ) was powered for a fixed interval for the light source, taking by camera (PCO.1600.) was carried out during the same interval, and image processing by VisiSizer (Oxford) was performed to analyze the droplet size. The number of approximately 1000-2000 droplets was captured for analysis of the droplet size. 
(c) Droplet velocity; Measurements of droplet velocity were performed using a PIV system with the water droplets themselves as the tracer, and analyzed by Koncerto ver. 2 (Seika Corporation).

\section{Flame spectral radiance measurement}

The spectral radiance was measured at a location of approximately $6.0 \mathrm{~m}$ from the fuel pan $\left(0.25 \mathrm{~m}^{2}\right)$ and height of $0.2 \mathrm{~m}$ from the top of the pan by using SR5000 (CI SYSTEM).

\section{Measurement of the radiant heat attenuation in a full-scale compartment}

The experiment was carried out in the full-scale fire compartment which has size of 6.25 (W) $\times 6.25$ (D) $\times$ $2.7(\mathrm{H}) \mathrm{m}$. Fig. 2(a) shows an outline of the experiment in case a fire source is placed in the compartment. A sprinkler was installed in the center of the compartment ceiling, and the area of sprinkling was made a semicircle $(1 / 2)$ by using a control chamber. Two radiant heat flux gauges (RE-III, Tokyo Seiko) were used, and the attenuation was determined via measurements taken by radiant heat flux gauge $[\mathrm{N}]$ which was not affect by water spray, and by radiant heat flux gauge [W] which was affected by water spray. Both were positioned at the same distance from the center of the fire source $(4.0 \mathrm{~m})$ and at the same height $(0.4 \mathrm{~m}$ from the top of the fuel pan). Furthermore, a total of 13 thermocouples (K-type, $0.32 \mathrm{~mm}$ in diameter) were positioned at $0.2-2.6 \mathrm{~m}$ spaced $0.2 \mathrm{~m}$ apart from the floor at a location $1 \mathrm{~m}$ from a corner inside the compartment in order to measure the temperature distribution within the compartment. Fig. 2(b) shows an outline of the experiment in case a fire source is placed outside the compartment. The effect of the smoke layer (soot) was removed through ordinary ventilation during fire. The area of sprinkling was set to $1 / 4$ by using a control chamber. The two radiant heat flux gauges were positioned in the compartment, and the radiant heat attenuation was measured. Both radiant heat flux gauges were positioned at the same distance from the center of the fire source $(6 \mathrm{~m})$ and the same height $(0.4 \mathrm{~m}$ from the top of the fire grate). In any cases, the combustion of the fire sources was not affected by the water spray.
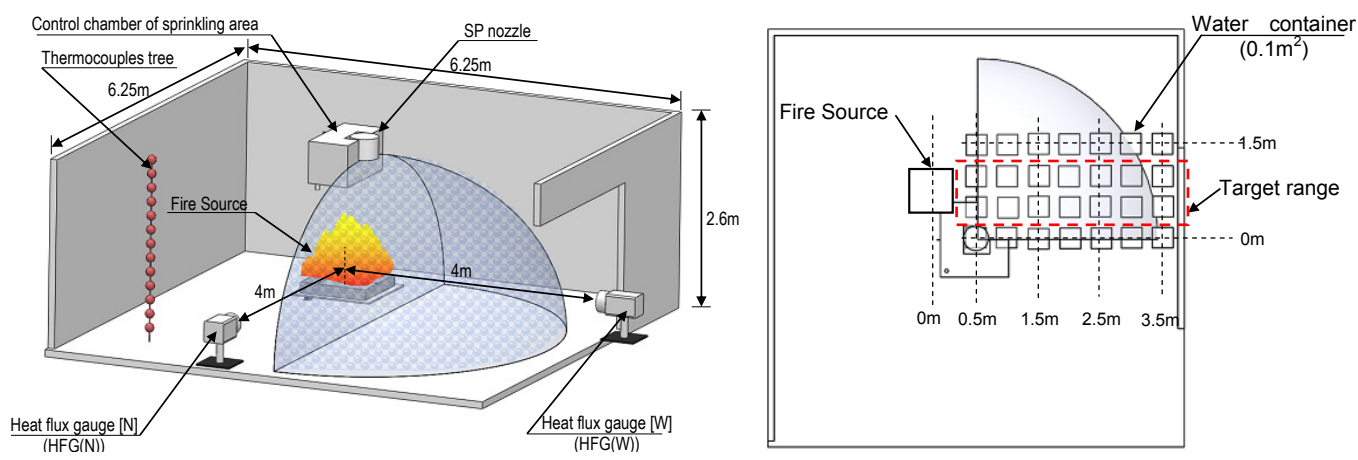

(a)

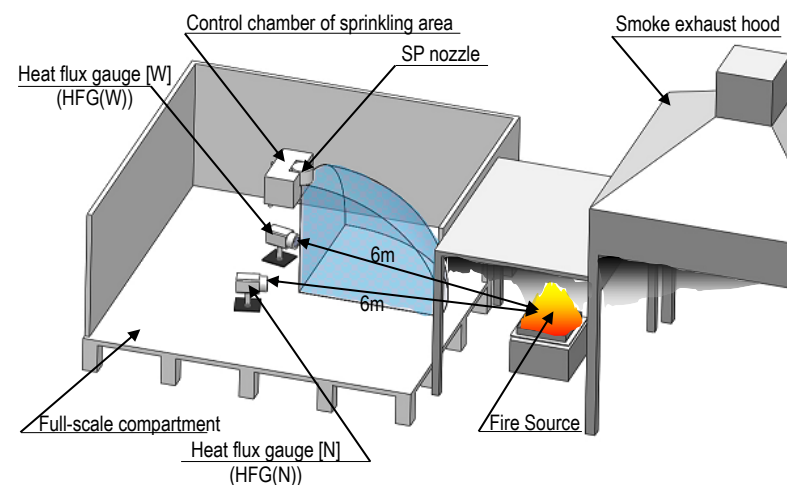

(b)

Fig. 2. Illustration of the fire experimental setup in case a fire source is placed (a) in the compartment and (b) outside the compartment. 


\section{Experimental Conditions and Measurement Items}

Table 1 shows the experimental conditions and measurement items. 5 varieties of sprinkler nozzles (heads) were used along with 2 varieties of fire sources, namely, $n$-heptane and ethanol, in order to compare the effect of a smoke.

Table 1. The experimental conditions and measurement items

\begin{tabular}{c||l|l|l|l|l|l}
\hline \multirow{4}{*}{$\begin{array}{c}\text { Sprinkler } \\
\text { heads }\end{array}$} & Common name & K30 & K50 & K80A & K80B & K80C \\
\cline { 2 - 7 } & $\begin{array}{l}\text { Water flow rate } \\
\text { (L/min) }\end{array}$ & 30 & 50 & 80 & 80 & 80 \\
\cline { 2 - 7 } & Type of nozzle & Flash & $\begin{array}{l}\text { Multi } \\
\text { water discharge pressure: } \\
0.1 \mathrm{MPa}\end{array}$ & $\begin{array}{l}\text { water discharge } \\
\text { pressure:0.1MPa }\end{array}$ \\
\cline { 2 - 6 } & Measurement items & $\begin{array}{l}\text { Sprinkling distribution, Water droplet size and } \\
\text { velocity }\end{array}$ \\
\hline \multirow{3}{*}{ Fire sources } & Kinds of fuel & n-heptane, and Ethanol \\
\cline { 2 - 6 } & Size of fuel pan & 0.5 $0.5 \mathrm{~m}\left(0.25 \mathrm{~m}^{2}\right)$ \\
\cline { 2 - 6 } & Measurement items & $\begin{array}{l}\text { Spectral radiance spectra, and Radiant heat } \\
\text { attenuation }\end{array}$ \\
\hline
\end{tabular}

The optical technique for a particle size measurement was employed, and the minimum margin was approximately $50 \mu \mathrm{m}$, and the distribution of water droplet size every SP nozzle is shown in Fig. 3. Based on this result, Sauter mean diameter was calculated every SP nozzle as follows

$a_{\text {ave }}=\frac{\sum n_{i} a_{i}^{3}}{\sum n_{i} a_{i}^{2}}$

A water droplet of 50-100 $\mu \mathrm{m}$ was dominant, but it was the effect was ignored because it was slightly approximately $0.015 \%$ at the overall volume ratio.

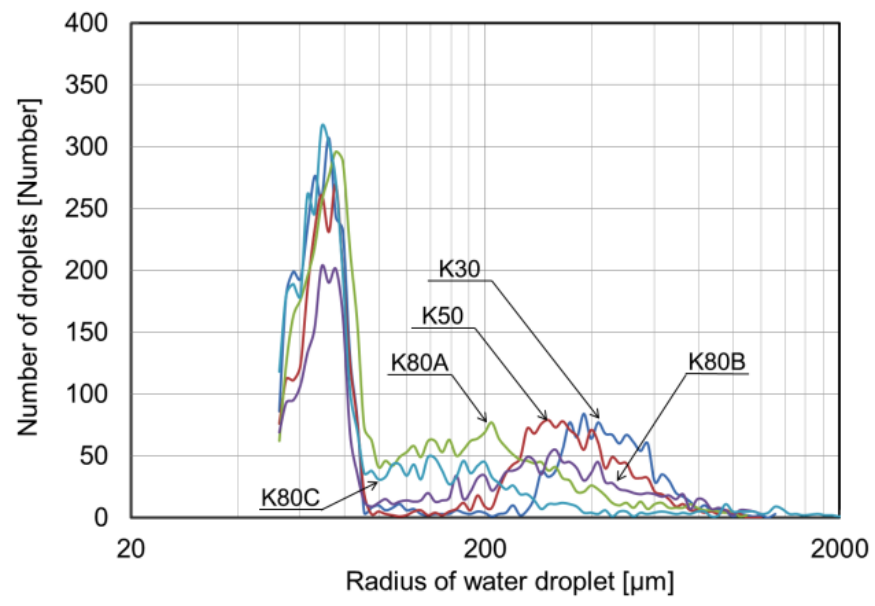

Fig. 3. Number of water droplet for water droplet radius each nozzles

\section{Experimental results}

\section{Fundamental characteristics of sprinkler nozzles}

Table 2 shows the measurement results for droplet size, velocity, and total quantity of water spray for each sprinkler nozzle. The Sauter mean diameter was used for the droplet size. The flash-type sprinkler was seen to produce droplets of a smaller diameter in comparison with the multi-type head, and even for the same 
flash-type, the tendency was seen for the droplets of the K50 and K80A to be smaller than those of the K30. No great difference was observed in droplet velocity between each sprinkler nozzle. Fig. 4(a) shows the results of mass flux water droplets for each sprinkler nozzle. Although variation in the distribution of water droplets was observed according to measurement location for the K80 at given flow rate, a significant difference did not arise in the total amount of water. Fig. 4(b) shows the results of calculating the water droplet density $n(x)$ for each sprinkler nozzle from the droplet size, droplet velocity, and distribution of water spray.

Table 2. Results of basic characteristics of sprinkler nozzles (heads)

\begin{tabular}{c|c|c|c|c|c}
\hline Common name & K30 & K50 & K80A & K80B & K80C \\
\hline \hline Mean of water droplet size $(\mu \mathrm{m})$ & 555 & 483 & 470 & 592 & 796 \\
\hline Mean of droplet velocity $(\mathrm{m} / \mathrm{s})$ & 3.65 & 3.6 & 3.6 & 3.4 & 3.6 \\
\hline $\begin{array}{c}\text { Amount of sprinkling distribution } \\
(\mathrm{L} / \mathrm{min})\end{array}$ & 367 & 639 & 1113 & 1269 & 1278 \\
\hline
\end{tabular}

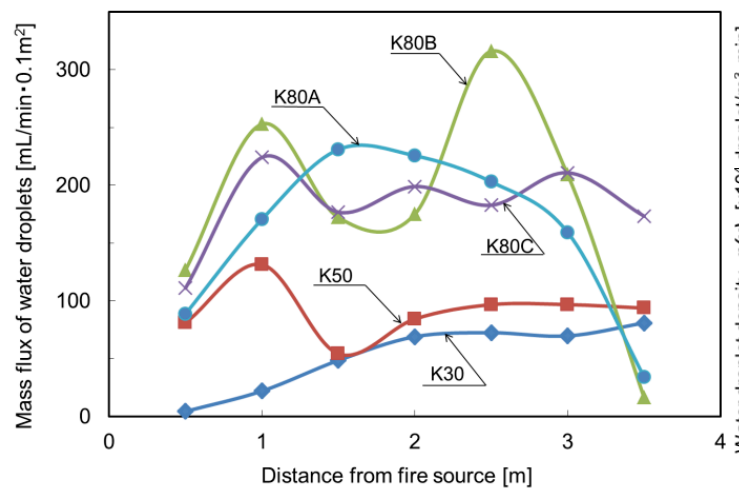

(a)

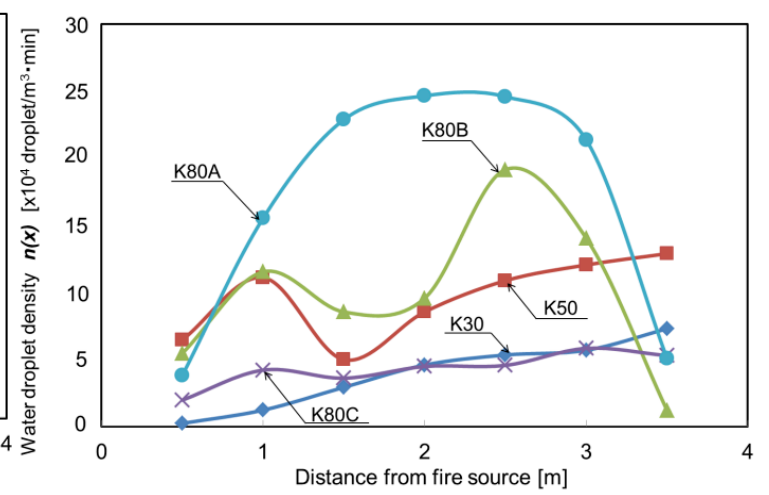

(b)

Fig. 4. Water droplet distribution of each nozzles (a) Measurement results of Mass flux water droplets and (b) Calculating results of the droplet density.

\section{Spectral radiance}

Fig. 10 shows the measurement results for the $n$-heptane and ethanol flame spectral radiance spectra. Because the emission spectrum changed according to a state of the combustion, the time average was employed during stable status of combustion, and the spectra were normalized such that the maximum value was 1.0. A sharp peak is apparent at $4.3 \mu \mathrm{m}$ in both spectra, which is the $\mathrm{CO}_{2}$ emission characteristic of a flame, and a peak was also visible at the $2.7 \mu \mathrm{m}$ emission characteristic of $\mathrm{H}_{2} \mathrm{O}$. Furthermore, a peak was visible in the vicinity of $2.0 \mu \mathrm{m}$ for the heptane flame, which produces a large quantity of soot, and the spectrum is similar to that of a black body radiator.

\section{Experimental results for radiant heat attenuation}

Fig. 5(a) shows the measurement results for the radiant heat flux for the case that the fuel for the combustion within the compartment and the sprinkler nozzle were ethanol and K80B, respectively. The sprinkler system was activated at $120 \mathrm{~s}$ after the fuel had been ignited. Prior to the sprinkler activation, the heat flux measurements by 2 heat flux gauges [W] and [N] showed almost the same value. It was also found that heat flux was decreased by the effect of water droplets, as heat flux gauge [W] showed a value lower than that of heat flux gauge $[\mathrm{N}]$ after the start of sprinkling. Fig. 5(b) shows the results for the case where the fuel for the combustion within the compartment was $n$-heptane and no water spray was used. Shortly after ignition, the value measured by heat flux gauge [W] surpassed that measured by heat flux gauge $[\mathrm{N}]$ after the smoke layer temperature was stable. It is supposed that the smoke layer has an influence. 


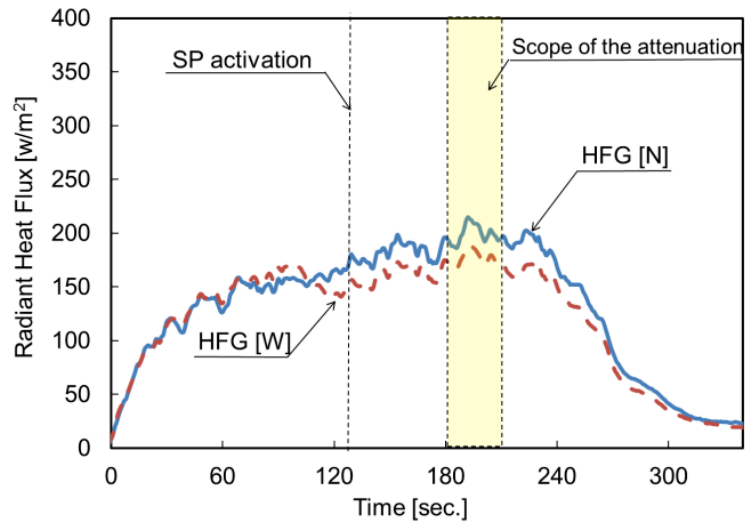

(a)

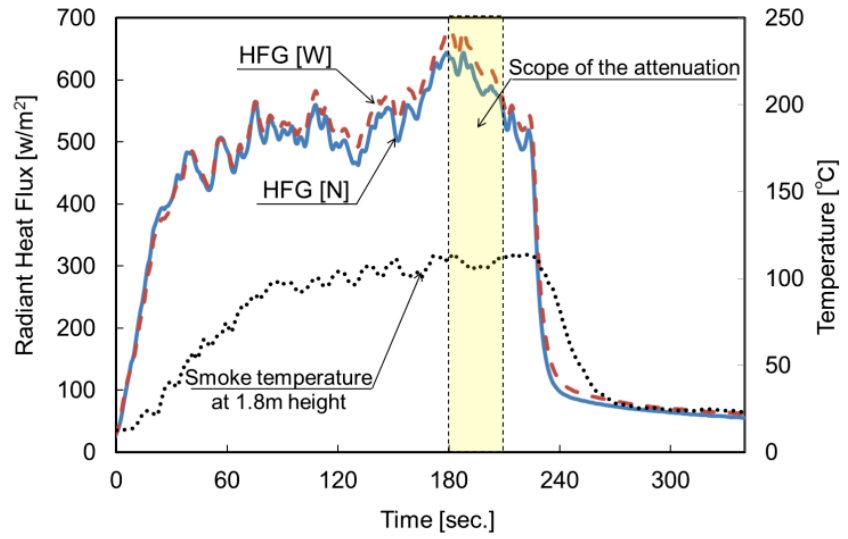

(b)

Fig. 5. Measurement results for the radiant heat flux within the compartment for (a) the case that the fuel and the sprinkler head were ethanol and $\mathrm{K} 80 \mathrm{~B}$, and

b) the case that the fuel was n-heptane and no water spray.

In the combustion of the $n$-heptane in the compartment, it was supposed influence by the smoke layer. Therefore, a correction was made by using a configuration factor with respect to the radiant heat each heat flux gauge receives from the smoke layer in order to remove this influence. Furthermore, the radiant heat attenuation factor by water spray was averaged over a $30 \mathrm{sec}$ period (from 180 to 210 after ignition) after the flame had stabilized after sprinkler activation, and was calculated as follows:

Attenuation factor $[\%]=\frac{H F G(N)-H F G(W)}{H F G(N)} \times 100$

Fig. 6(a) shows the attenuation factor for ethanol. In the case that ethanol was used as the fire source, no great difference was observed inside and outside the compartment, as almost no soot was contained in combustion product. Fig. 6(b) shows the attenuation factor for $n$-heptane flame. The values corrected for the radiant heat from the smoke layer are also shown. From the left, the plots are shown for K30, K50, $\mathrm{K} 80 \mathrm{~A}, \mathrm{~K} 80 \mathrm{~B}$, and $\mathrm{K} 80 \mathrm{C}$, with the origin indicating free combustion (no water spray). There is scatter in all measurements, but the radiation attenuation factor can be seen to increase in accompaniment with an increase in quantity of water spray. This is caused by the infrared energy emitted from the fire source being absorbed by the water droplets. 


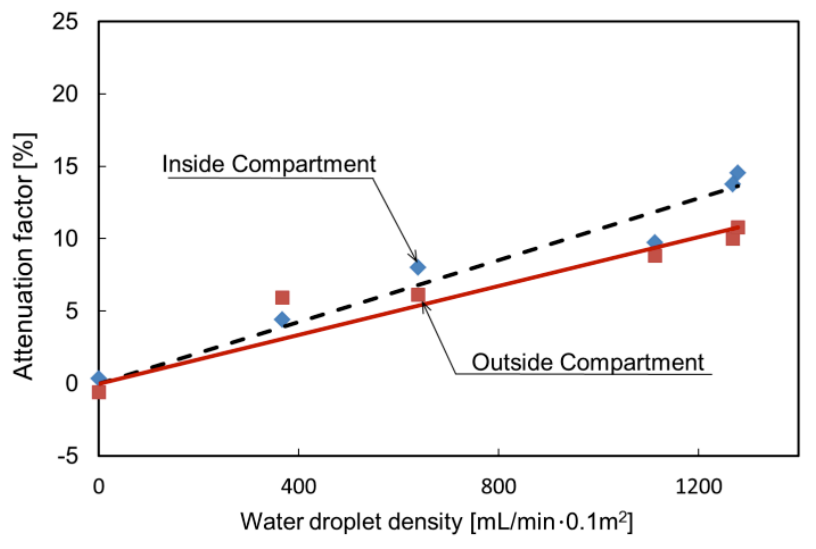

(a)

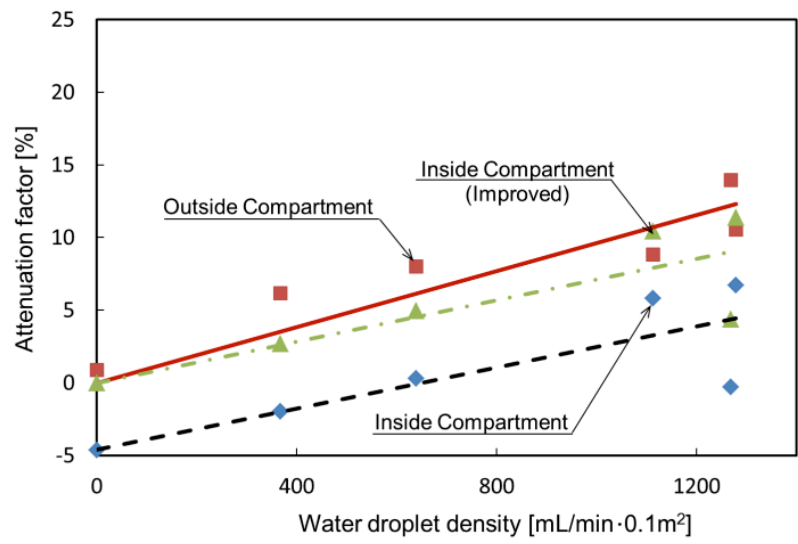

(b)

Fig. 6. Attenuation factor compared between inside and outside the compartment for (a) ethanol flame, and (b) $n$-heptane flame.

\section{ESTIMATION OF RADIANT HEAT ATTENUATION BY THE MIE THEORY}

\section{The Mie Theory}

The development of a predictive calculation model for radiant heat attenuation is attempted by using the Mie theory [6]. A schematic diagram of the Mie theory is shown in Fig. 7. The light (electromagnetic waves) incident on a particle is absorbed by the particle or separated into incident light and scattered light with a different angle. The indices that show the strength of these phenomena are the absorption coefficient $\left(Q_{\text {abs }}\right)$ and the scattering coefficient $\left(Q_{\text {sca }}\right)$. The values of both of these coefficients depend on the spectrum of the incident light and the particle size. Also, the function that shows the relationship between incident wavelength and scattering strength/angle is defined as the phase function $P(\theta)$, and forward scattering is said to become dominant when the particle size is large in relation to the wavelength.

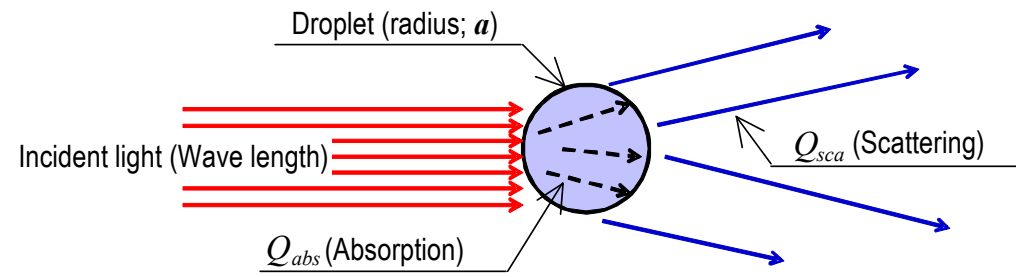

Fig. 7. A schematic diagram of the Mie theory. 


\section{Comparison of Experimental Results and Calculated Values}

Fig. 8 shows the calculation results for the phase function of water droplets with respect to a wavelength of $4.3 \mu \mathrm{m}$. Scattering was ignored as approximately $99 \%$ of the scattering light was concentrated in a range of approximately $1^{\circ}$ and forward scattering (penetration) was dominant. Consequently, a calculation method by a two-flux method ignoring scattering as shown by equations (3) and (4) was followed as in past research [5]. This is an expansion of the absorption by a single particle to that of an infinite number of particles.

$$
\begin{aligned}
& \frac{1}{2} \frac{d I_{\lambda d}}{d x}=n(x) \cdot \pi a^{2} \cdot Q_{a b s} \cdot I_{\lambda m} \\
& I=e_{\lambda} \times \int I_{\lambda d}(x) d x
\end{aligned}
$$

where, $n(x)=\frac{3 D(x) \sqrt{x^{2}+Y^{2}+Z^{2}}}{4 \pi a^{3} v Z}$

The empirical data shown in Fig. 3 were used for $n(x)$. $Q_{\text {abs }}$ was calculated by the Mie theory, and some of calculation results are shown in Fig. 9. It was found that wavelengths greater than $2.7 \mu \mathrm{m}$ were mostly absorbed irrespective of the droplet size, and wavelengths less than this had a tendency to be more easily absorbed as the droplet size increased.

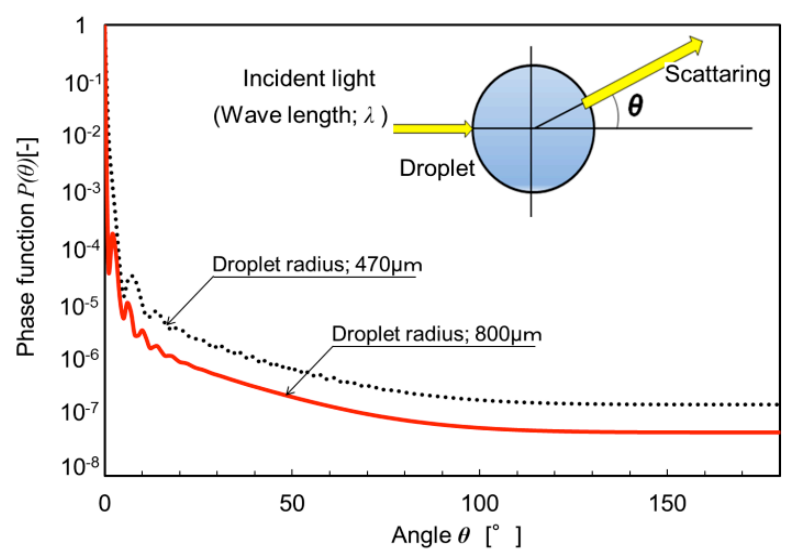

Fig. 8. Phase function $P(\theta)$ of water droplet.

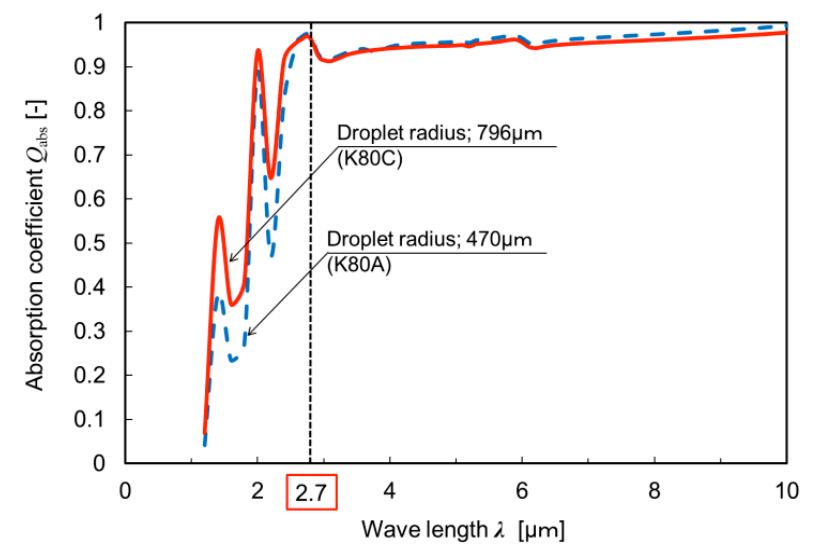

Fig. 9. Absorption coefficient $\left(Q_{\text {abs }}\right)$ of water droplet. 
The results of the radiant heat attenuation factor calculation for the $n$-heptane flame are shown in Fig. 10 as a representative example. Both the experimental results and the calculated values are generally in agreement, and the calculation showed especially good agreement with the results for the experiment conducted outside the compartment, which removed the influence of the smoke layer (soot). Accordingly, absorption by water droplets was dominant in the attenuation of radiant heat, and a sufficiently accurate prediction was possible by means of a model based on the Mie theory.

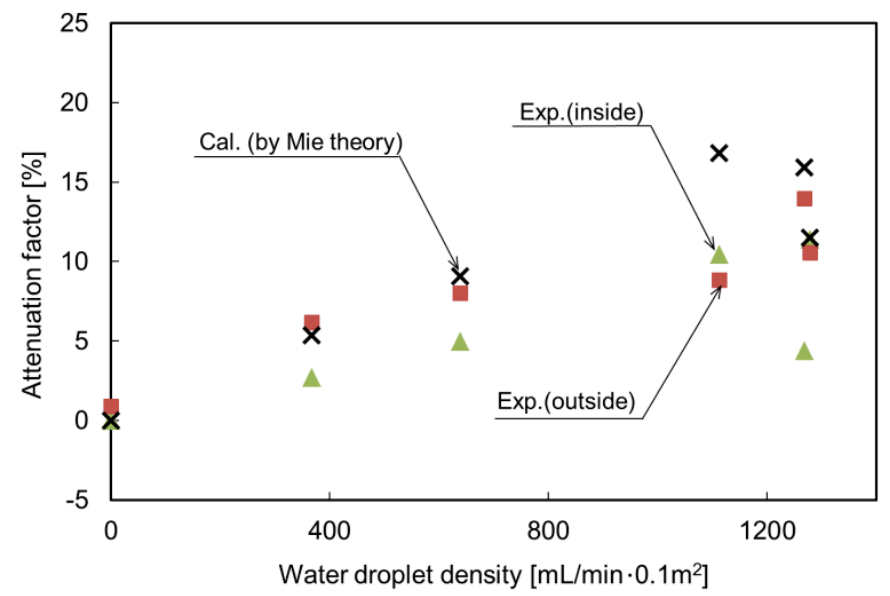

Fig. 10. Comparison between experimental data and value calculated by Mie theory regarding to attenuation factor.

\section{ESTIMATION MODEL FOR FLAME SPECTRAL RADIANCE}

To use the Mie theory for estimating the absorption of radiant heat by droplets, the spectral radiance of the flame is necessary. However, since known flame spectral radiance data for the infrared region are limited, a predictive calculation for radiant heat attenuation due to the droplets is possible if the flame spectral radiance can be estimated. In this paper, spectral radiance estimation was attempted by an improved model based on an existing narrowband model (RADCAL)[7]. With this model, an emission spectrum is calculated from factors including the flame temperature, soot density, and the partial pressure of the gas generated during the chemical reaction.

\section{Verification of the Model (n-heptane)}

Fig. 11 shows a comparison of values calculated by the estimation model for flame spectral radiance and experimental data for the case of $n$-heptane flame. Some differences can be seen, but these are caused by a property of the burning behavior. The model is judged to be sufficiently adaptable because the characteristic peaks are reproduced.

\section{Verification of Radiant Heat Attenuation Predictions using a Flame Model}

To verify the availability of the improved model which can predict emission spectrum from flame for various fuels, Fig. 12 shows the results of radiant heat attenuation calculations by the Mie theory using the experimental values and the model depicted in Fig. 11. The results shown in Table 2 and Fig. 3 were used as the sprinkler nozzle data. Good agreement was seen in both the calculation results, and the model was judged to be sufficiently adaptable. 


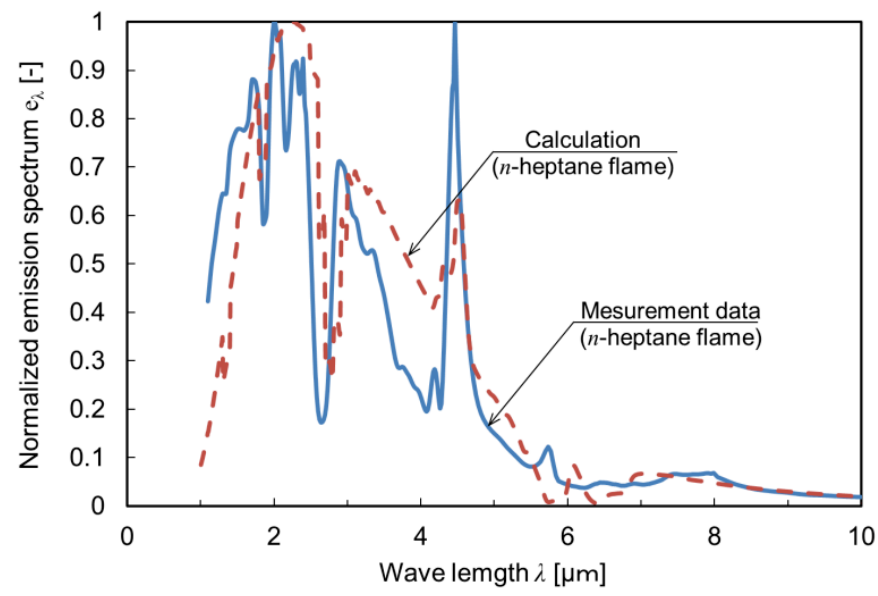

Fig. 11. Comparison between measurement data and prediction model by improved narrowband model

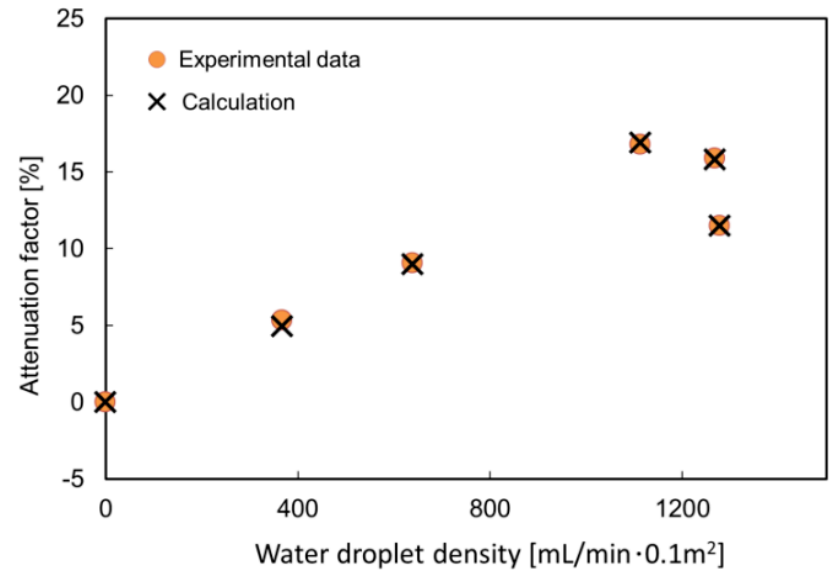

Fig. 12. Comparison of attenuation factor between experimental data and prediction by using emission spectrum by the improved narrowband model.

\section{ESTIMATION OF RADIANT HEAT ATTENUATION}

The aforementioned experimental and theoretical investigation enabled radiant heat attenuation prediction using factors such as the absorption coefficient calculated from the means of water droplets distribution, droplet size, and the flame spectral radiance. In this section, a case study is carried out using the developed predictive model in order to compare the effects of radiant heat attenuation according to differences in mass flow rate of water spray and droplet size by using these factors as parameters. The $n$-heptane flame shown in Fig. 11 is used as a representative example of the fire source.

\section{Radiant Heat Attenuation in Response to Mass Flow Rate of Water Spray}

Fig. 13(a) shows the change of attenuation factor with respect to sprinkling quantity. When the mass flow rate of water spray increases, the radiant heat attenuation factor increases linearly, and this trend becomes more pronounced as the droplet size decreases. This is in agreement with the trend in the experimental results shown in the previous section.

\section{Radiant Heat Attenuation in Response to Droplet Size}

Fig. 13(b) shows the change in attenuation factor with respect to droplet size. The attenuation factor can be predicted to increase as droplet size decreases. This is because the surface area that absorbs the radiant heat increases for the same mass flow rate of water spray for a smaller droplet size. Consequently, it is possible that a smaller droplet size can more effectively isolate radiant heat. However, in an actual system, it is 
necessary to consider that if the droplet size is too small, then the water will evaporate due to the radiant heat from the flames or be drawn into a draft generated by the flames without reaching the fire source, and the system will not function well.

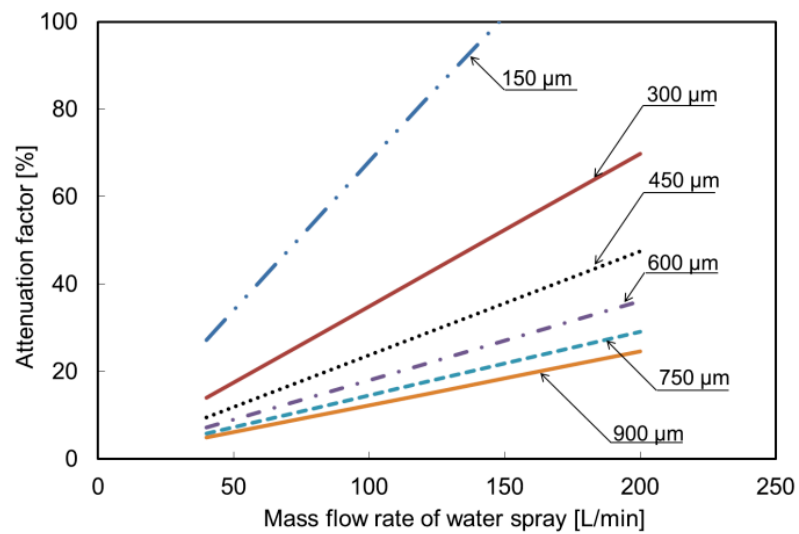

(a)

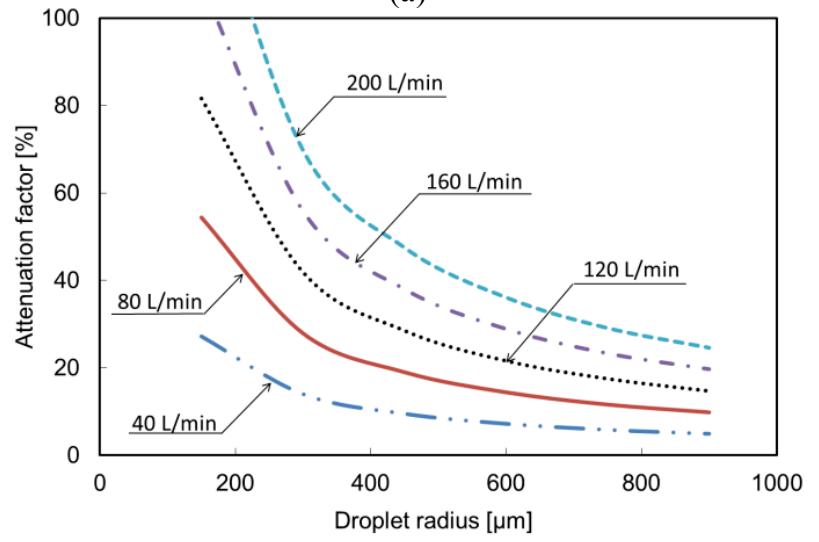

(b)

Fig. 13. Predictions of attenuation factor for (a) Mass flow rate of water spray and (b) Droplet radius.

\section{CONCLUSION}

The results obtained in this study are as follows.

- By performing a systematic full-scale fire experiment in addition to ascertaining the fundamental characteristics of sprinkler nozzles, radiant heat attenuation by water droplets was demonstrated.

- The results of radiant heat attenuation calculations based on the Mie theory were found to be in agreement with experimental values. The attenuation of radiant heat therefore means the absorption of infrared energy by water droplets.

- The predictive model for flame spectral radiance showed also good agreement with measurement values. Furthermore, since good agreement was found in the radiant heat attenuation prediction based on the Mie theory, it is possible to predict the quantity of radiant heat attenuation by inputting fuel/sprinkler nozzle characteristics.

- When the attenuation of radiant heat from the flame was estimated with droplet size and mass flow rate of water spray as parameters, the attenuation factor tended to linearly increase in response to an increase in mass flow rate of water spray.

- As a result of the parametric study on the attenuation of radiant heat from a fire, the tendency was found where the attenuation factor increased as droplet size decreased at the same mass flow rate of water spray, because the surface area that can absorb the radiant heat increases for the same mass flow rate of water spray in the case that the droplet size is smaller. 


\section{REFERENCES}

[1] Tanaka, F., Ohmiya, Y., Takahashi, Y., Takase, F. and Nakao, T., 2007. Fire Characteristic of Full Scale Compartment with an Activation of Water Discharge System, Journal of Environmental Engineering (Transaction of Architectural Institute of Japan (AIJ)), No. 614, pp.1-7 (in Japanese).

[2] Ravigururajan, T.S. and Beltran, M.R., (1989). A Model for Attenuation of Fire Radiation through Water Droplets, Fire Safety Journal, Vol. 15, pp.171-181. http://dx.doi.org/10.1016/03797112(89)90002-7

[3] Tseng, C.C. and Viskanta, R., (2007). Absorptance and Transmittance of Water Spray/Mist Curtain, Fire Safety Journal, Vol. 42, pp.106-114, http://dx.doi.org/10.1016/j.firesaf.2006.08.005

[4] A. Coppalle, D. Nedelka and B. Bauer, (1993). Fire protection: Water curtains, Fire Safety Journal, Vol. 20, pp.241-255, http://dx.doi.org/10.1016/0379-7112(93)90046-S

[5] Sunahara, H., Ishihara, T., Matsuyama, K., Sugahara, S. and Morita, M., (2011). Relation between Heat Release Rate and Radiative Heat Flux of Wooden Crib Burning during Water Discharge, Fire Science and Technology, Vol.30, pp.1-25. http://dx.doi.org/10.3210/fst.30.1

[6] Bohren, C.F. and Huffman, D.R., 1998. Absorption and Scattering of Light by Small Particles, Wiley-VCH.

[7] W. L. Grosshandler, "RADCAL: A Narrow-Band Model for Radiation. Calculations in a Combustion Environment”, NIST Technical Note 1402, 1993. 